Cahiers $d u$ MONDE RUSSE

\section{Cahiers du monde russe}

Russie - Empire russe - Union soviétique et États indépendants

$46 / 4 \mid 2005$

L'invention d'une politique humanitaire

\title{
Catherine Gousseff, Anna Sossinskaïa, éds., Les enfants de l'exil
}

\section{Laura Lee Downs}

\section{(2) OpenEdition}

Journals

Édition électronique

URL : https://journals.openedition.org/monderusse/6669

DOI : $10.4000 /$ monderusse. 6669

ISSN : $1777-5388$

\section{Éditeur}

Éditions de l'EHESS

\section{Édition imprimée}

Date de publication : 1 décembre 2005

Pagination : 982-985

ISBN : 2-7132-2057-2

ISSN : $1252-6576$

Référence électronique

Laura Lee Downs, "Catherine Gousseff, Anna Sossinskaïa, éds., Les enfants de l'exil », Cahiers du monde russe [En ligne], 46/4 | 2005, mis en ligne le 30 juin 2009, consulté le 02 septembre 2022. URL http://journals.openedition.org/monderusse/6669; DOI : https://doi.org/10.4000/monderusse.6669

Ce document a été généré automatiquement le 2 septembre 2022

Tous droits réservés 


\title{
Catherine Gousseff, Anna Sossinskaïa, éds., Les enfants de l'exil
}

\author{
Laura Lee Downs
}

\section{RÉFÉRENCE}

Catherine GOUSSEFF, Anna SOSSINSKAÏA, éds., Les enfants de l'exil. Récits d'écoliers après la Révolution de 1917. Paris : Bayard, 2005, 265 p.

« Je suis né en 1908 à Pavlovsk. Dans ma petite enfance, je ne devais me soucier de rien [...]. Mais cela n'a pas duré longtemps parce que les Bolcheviques sont apparus en 1917 [...]. Notre famille a dû quitter son foyer natal et aller là où il n'y avait pas de Bolcheviques. Durant les premiers jours, notre famille est restée réunie. Mais, puisque j'ai voyagé dans une tout autre charrette que celle de mon père et par un tout autre chemin, j'ai perdu mes parents et j'ai dû continuer la route par moimême. C'était en 1917, le 15 septembre. Depuis, je n'ai plus revu mes parents... » (Victor Zelenev, «L'enfant perdu », p. 151).

Dire que les guerres du $\mathrm{xx}^{\mathrm{e}}$ siècle n'ont pas épargné les enfants est presque une banalité. Or, il est tout sauf banal d'écouter les voix des enfants - victimes, réfugiés ou parfois participants - dans ces mêmes guerres. Car, comme le notent les éditeurs des 56 récits recueillis dans Enfants de l'exil, le témoignage des enfants est singulier, « dégagé du poids de la responsabilité qui oriente nécessairement celui des adultes » (p. 257). D'où l'intérêt considérable de ce beau livre, publié par l'historienne Catherine Gousseff et la psychologue Anna Sossinskaïa. Les deux chercheuses ont su laisser la parole aux jeunes eux-mêmes; elles n'interviennent qu'à la fin de l'ouvrage, dans un bref « Commentaire historique » qui donne aux lecteurs quelques repères dans le paysage turbulent de ces années 1917-1921, marquées par la révolution, puis la guerre civile et la famine. Ce sont dès lors les voix des enfants qui retentissent dans ces pages terribles, des voix qui racontent sous 56 formes différentes comment ils ont tout perdu : foyer familial, parents, frères et sœurs, pays natal enfin. 
D'où viennent tous ces témoignages déchirants sur la révolution et la guerre civile, vues par des filles et des garçons qui avaient, à l'époque des événements, entre 3 et 18 ans ? En décembre 1923, le directeur du lycée russe de Moravie (Tchécoslovaquie) invita ses élèves, tous exilés de Russie, à rédiger une rédaction sur le thème « Mes souvenirs depuis l'année 1917 jusqu'au jour de mon entrée au lycée ». Chaque écolier disposait de deux heures (plus ou moins) pour rédiger cette narration, ce qui a eu pour résultat des textes courts, voire inachevés parfois. En même temps, comme le remarquent les éditeurs, c'est dans ce « condensé en quelques pages d'années si denses et cruciales que ressort à vif ce qui a le plus marqué le vécu du chaos» (p. 257). Au printemps 1924, les directeurs d'une quinzaine de lycées russes créés dans différents pays de la diaspora (Bulgarie, Turquie, Tchécoslovaquie, Yougoslavie) incitent leurs élèves à procéder au même exercice. À la fin du printemps, le Bureau pédagogique de Prague, créé dans le but d'harmoniser tous les programmes des écoles russes fondées en exil, comptabilise 2403 rédactions de filles et de garçons qui ont fui la Russie entre 1919 et 1921. Catherine Gousseff et Anna Sossinskaïa en ont choisi 56 en se fondant sur un souci de représentativité, tant par le sexe ou les origines sociales de l'enfant que par sa classe d'âge et l'expérience vécue pendant la révolution et la guerre civile (réfugié, enfant soldat, orphelin, etc.).

3 Tous ces enfants proviennent des milieux privilégiés de la société d'Ancien Régime ; une majorité sont des filles et fils d'officiers, y compris de cosaques. N'ayant que de 3 à 18 ans au moment où la révolution éclate, ils n'ont connu que la guerre, qui fait rage depuis 1914, avant de se muer en révolution, puis en guerre civile à partir de 1918-1919. Si leurs récits ont tous la même forme - une période d'enfance heureuse et protégée, suivie d'un « réveil » brutal aux réalités de la violence qui les entoure -, les éditeurs trouvent que cette répétition dans la forme, sinon dans le contenu des récits, " accentue la valeur de ces documents historiques révélateurs des faits qui ont le plus touché, voire traumatisé les enfants» (p. 242). En même temps, la particularité de chaque récit réside dans les modalités du « réveil » de l'enfant aux réalités brutales d'un monde bouleversé par les violences de la guerre. Ainsi, tous ces « réveils » individuels, qui sont provoqués soit par le fait d'avoir assisté à des scènes sanglantes et meurtrières, soit par la perte de personnes chères à l'enfant, sont aussi des moments de transition dans le récit entre le paradis de l'enfant, caractérisé par les jeux et l'absence de soucis, et le passage soudain à l'état adulte, effectué brusquement dans le chagrin et/ou la terreur: "Quatre mois passés au front m'ont rendu tout à fait adulte et étonnamment calme et posé », raconte un adolescent qui n'avait pas encore 13 ans lorsque éclate la révolution d'Octobre. « La mort ne m'effrayait pas et mes nerfs étaient devenus semblables à des câbles marins » (p. 194).

4 Ce que j'appelle le moment du « réveil » de l'enfant dans la structure narrative de ces 56 récits est nommé « traumatisme » par les éditeurs. À leurs yeux, c'est le moment d'une «rupture intérieure profonde qui mûrit trop précocement certains enfants» (p. 244). Effectivement, tous les souvenirs recueillis relatent plus ou moins explicitement le fait que la période de la guerre et de l'exil a entraîné non seulement la perte des proches et du pays natal, mais aussi celle de l'enfance: «Avant je montais à cheval, je m'entraînais à tirer, je galopais dans les montagnes du Caucause et dans les steppes du Don", écrit Svetlana Fenina, exilée en Égypte, puis en Tchécoslovaquie. « Et maintenant, depuis mon départ de Russie, je devais transformer le garçon que j'étais en fille douce, sage. Au début j'étais très triste, mais après je me suis habituée » (p.85). Or, sur le chemin de la fuite, certains de ces enfants constatent une perte encore plus terrible, celle de leur sensibilité humaine, qui se signale par une indifférence terrifiante devant la souffrance des autres: 
"Je suis devenu presque psychopathe, un handicapé moral, inculte, remonté contre tous, terrorisé comme un loup » écrit un garçon, effrayé par l'impact sur son âme des maintes violences qu'il a vécues. « Mon passage au front et à l'armée ont enlaidi ma jeune âme et mon cœur", raconte un autre enfant devenu soldat en 1918. Un troisième remarque simplement que sa vie pendant la révolution « a ressemblé à celle d'un animal qui n'avait aucun souci sauf celui du ventre » (p. 244-245, 171 et 184).

$5 \mathrm{Si}$, au début du xxi ${ }^{\mathrm{e}}$ siècle, la psychologue peut lire dans ces mots le signe externe d'une rupture intérieure profonde, un traumatisme qui oblige les enfants à grandir vite afin de s'adapter au monde brutal de la guerre civile, les enfants de l'exil, eux, ne disposaient pas de telles ressources psychologiques. Ce manque de réconfort moral ressurgit de façon terrible dans les souvenirs des enfants soldats, qui furent non seulement témoins, mais aussi acteurs de la violence : «Quelquefois, il m'est arrivé de voir comment on fusillait et d'y participer ", écrit un garçon qui avait 16 ans en 1918.

«Avec beaucoup de curiosité et sans aucune pitié, je tirais sur le condamné. Ensuite, après avoir tiré, mon corps et mon âme étaient pris par un tremblement nerveux à cause de la conscience confuse de mon propre tort. Beaucoup plus tard, j'ai compris ce grand péché que j'accomplissais de sang-froid et avec curiosité. J'ai compris et j'ai été horrifié. C'est seulement maintenant que je me rappelle ce qui s'est passé, avec un profond remords sans issue » (p. 221-222).

$6 \quad$ La spécificité de ce recueil de souvenirs tient au fait que tout est raconté du point de vue des enfants, par des jeunes qui sont, sept ans après la révolution d'Octobre, encore proches de ce qu'ils ont vécu en 1917 et les années suivantes. De fait, les plus jeunes de ces auteurs sont toujours des enfants en 1923-1924. Ces textes représentent leur perspective particulière. Ils portent l'empreinte de la curiosité de leurs jeunes auteurs devant les événements de Février puis d'Octobre 1917, curiosité qui n'est souvent accompagnée d'aucun sentiment de peur : "Tout ça m'a terriblement excitée », raconte une fille qui n'avait que six ans en 1917. « Une fois... on a entendu des cris dans la rue et nous sommes sortis sur le perron et nous avons vu une masse de peuple avec des drapeaux rouges et qui criait quelque chose. Ça m'a beaucoup plu et j'ai demandé à la gouvernante : “Quoi, cela va être comme ça chaque année" ?» (p. 91). Un autre enfant, qui avait 9 ans en 1917, se souvient qu'il avait peur - et il ajoute : «mais en même temps j'avais terriblement envie de voir, ne serait-ce qu'une fois, les affrontements dans la rue » (p. 23).

Ces témoignages, si marqués par la curiosité et l'excitation des enfants devant le " jeu » de la révolution, se distinguent des témoignages adultes aussi par la particularité de ce qui retient l'attention des jeunes narrateurs : les odeurs, le vrombissement des obus, la pluie fine et tiède de printemps qui tombe lors d'un déplacement à pied, les cadavres de chevaux sur le bord de la route, le sang sur les murs après une fusillade. La mémoire enfantine semble être organisée par d'autres critères que celle des adultes. Ainsi, le récit de la perte de leur monde familier se décline moins par la chronologie politique des années 1917-1921 que par des événements plus immédiats qui sont gravés dans leur mémoire au travers des sensations acoustiques, olfactives et visuelles qui les accompagnent.

8 S'il convient de distinguer la perception ou mémoire enfantine de celle de l'adulte, il faut aussi différencier les classes d'âge. Les éditeurs consacrent un chapitre entier aux « Tout-petits de la guerre », ceux qui ont entre 3 et 12-13 ans en 1917-1918. Ces récits sont moins structurés que ceux de leurs aînés, les faits relatés apparaissant pêle-mêle dans une énumération « dépourvue d'émotions » ou transcrites par quelques formules types: « j'ai pleuré », «j'étais bien», «j'étais mal » (p. 241). À partir de 12-13 ans, les récits sont 
mieux construits chronologiquement et le contexte politique est plus souvent évoqué, même si l'enfant lui-même avoue sa propre distance par rapport au monde politique: "Je n'avais aucune conviction politique », écrit un garçon qui avait 13-14 ans en 1918. «Je ne comprenais absolument rien à la politique et je suis allé là où on m'envoyait combattre, souffrir, tuer mon propre frère ", rappelle-t-il dans une condamnation sévère des adultes qui se servaient de son innocence pour servir leurs propres fins politiques (p. 154). D'autres adolescents se livrent à des réflexions sur l'émergence en eux d'une conscience politique, ou plutôt "proto-politique ", lorsque la révolution éclate : "J'ai entendu autour de moi des termes divers, alors incompréhensibles pour moi: "socialistes", "démocrates", "populistes" et autres du même genre ", raconte un garçon qui avait 11 ans en 1917.

«Mais les événements qui se jouaient autour de nous se faisaient sentir; nous les petits, on commençait déjà à déchiffrer qui était notre ami à nous et qui était l'ennemi, et ces opinions purement instinctives se transformaient en fermes convictions. Nous avions compris que le parti des Bolcheviques qui avait pris le dessus était notre ennemi » (p. 179).

$9 \quad$ Les 56 textes des Enfants de l'exil ouvrent donc une porte sur la structure de la pensée enfantine et sur la diversité des perceptions des jeunes devant la destruction de leur monde familier. Ce livre jette aussi quelques lumières sur les convictions pédagogiques des organisateurs des lycées russes en exil. Rejetant la formule du placement familial pour ces orphelins de l'orage, ceux-ci étaient convaincus de la vertu thérapeutique du placement collectif et regroupèrent les écoliers en internats conçus comme des « îlots de terre russe ». À la différence des experts de l'enfance au sortir de la Seconde Guerre mondiale, ces responsables parlaient tous en termes de reconstruction d'une communauté russe dans la diaspora comme base du bien-être enfantin. Ils cherchaient à faire de leurs pensionnats des lieux où les élèves seraient « censés pouvoir vivre comme chez eux, dans l'entourage d'une langue familière qui les protégeait de l'étrangeté de l'exil, dans la sécurité d'une discipline destinée à recréer des repères sûrs, dans un environnement pacifiant où la religion prenait une place importante, où la collectivité était assimilée à une grande famille » (p. 256).

Enfin, Les enfants de l'exil illustre ce qui n'est qu'évoqué dans les récits eux-mêmes, à savoir l'environnement des lycées russes, à travers une cinquantaine de photos qui montrent les enfants dans leurs salles de cours, en récréation, faisant du jardinage ou des travaux ménagers, au cours de gymnastique, ou encore jouant des instruments de musique traditionnels. Ces photos permettent au lecteur de jeter un coup d'œil sur la " grande famille russe » reconstruite dans la diaspora à travers les études, la musique, et le devoir de mémoire que constitua la rédaction des souvenirs de chacun depuis l'année 1917. Grâce aux interventions fines et subtiles de Catherine Gousseff et Anna Sossinskaïa, le lecteur arrive à comprendre que ce devoir de mémoire faisait partie d'une pédagogie active plus large qui engageait chaque enfant de l'exil dans la reconstruction de son être à travers la vie de la communauté et la mémoire de ce qui était perdu à jamais. 